\title{
SOLUSI NUMERIK PERSAMAAN GELOMBANG KORTEWIEG DE VRIES (KDV)
}

(Numeric Solutions of Kortewieg de Vries' Wave Equation)

FRANCIS Y. RUMLAWANG

Jurusan Matematika, FMIPA,Universitas Pattimura Ambon

Jl. Ir. M. Putuhena, Kampus Unpatti, Poka-Ambon

E-mail: rumlawang@gmail.com

\begin{abstract}
One of $\mathrm{KdV}$ wave form is $u_{t}+6 u u_{x}+u_{x x x}=0$. This paper deals with finding numerical solutions of KdV's equation which form a running wave $u(x, t)=u(x-\lambda t)$, by using Stepeest Descent Method which is charged on Hamilton $H(u)$ and Momentum $M(u)$. By using MAPLE software, we obtain numerical solutions of $\mathrm{KdV}$ equation in the form of running wave profile.
\end{abstract}

Keywords: Kortewieg de Vries, numerical solution, wave equation

\section{PENDAHULUAN}

Diketahui persamaan $\mathrm{KdV}$

$$
u_{t}+6 u u_{x}+u_{x x x}=0
$$

dapat ditulis dalam bentuk lain

$$
\partial_{t} u=\partial_{x}\left(-u_{x x}-3 u^{2}\right)
$$

Persamaan ini dapat ditulis dalam bentuk hamiltonian sebagai:

$$
\partial_{t} u=\partial_{x} \delta H(u)
$$

dengan

$$
H(u)=\int\left(\frac{1}{2} u_{x}^{2}-u^{3}\right) d x
$$

Hamilton $H$ yang menyatakan energi invariant terhadap waktu. Terdapat juga invariant lain yaitu massa $m$ dan momentum $\mathrm{M}$ yang diberikan oleh

$$
\begin{aligned}
& m(u)=\int u d x \\
& M(u)=\int u^{2} d x
\end{aligned}
$$

Sekarang kita akan mencari solusi persamaan KdV yang berupa gelombang jalan yang berbentuk $u(x, t)=u(x-\lambda t)$ dengan $\lambda$ menyatakan cepat rambat gelombang tersebut. Misalkan $u$ direpresentasikan dalam sejumlah hingga suku dari deret Fourier maka:

$$
u(x, t)=\sum_{k=1}^{N}\left(a_{k}(t) \cos (k x)+b_{k}(t) \sin (k x)\right)
$$

Tulisan ini akan merepresentasikan $u$ dalam 2 suku dari deret Fourier sehingga berbentuk:

$$
\begin{aligned}
u(x, t)= & \sum_{k=1}^{2}\left(a_{k}(t) \cos (k x)+b_{k}(t) \sin (k x)\right) \\
= & a_{1}(t) \cos x+b_{1}(t) \sin x+a_{2}(t) \cos 2 x+ \\
& b_{2}(t) \sin 2 x
\end{aligned}
$$

Substitusikan persamaan ini ke persamaan (1) dengan membuang suku yang lebih tinggi misal $\sin 3 x, \sin 4 x$ dan seterusnya, kemudian disamakan koefisien-koefisiennya akan diperoleh sistem persamaan differensial yang berbentuk:

$$
\begin{aligned}
& \dot{a}_{1}(t)=\frac{d a_{1}}{d t}=b_{1}(t)-3 a_{1}(t) b_{2}(t)+3 a_{2}(t) b_{1}(t) \\
& \dot{b}_{1}(t)=\frac{d b_{1}}{d t}=-a_{1}(t)+3 a_{1}(t) a_{2}(t)+3 b_{1}(t) b_{2}(t) \\
& \dot{a}_{2}(t)=\frac{d a_{2}}{d t}=8 b_{2}(t)-6 a_{1}(t) b_{1}(t) \\
& \dot{b}_{2}(t)=\frac{d b_{2}}{d t}=-8 a_{2}(t)+3 a_{1}(t)^{2}-3 b_{1}(t)^{2}
\end{aligned}
$$

Sistem persamaan ini notabene sulit untuk diselesaikan secara analitis oleh karena itu akan dilakukan pendekatan numerik

\section{METODE PENELITIAN}

Dengan demikian kita akan menentukan profil gelombang jalan dengan melakukan hampiran Fourier pada sistem hamiltonnya.

Substitusikan persamaan (8) ke (4) dan (6) maka akan diperoleh 


$$
\begin{gathered}
H\left(a_{1}, b_{1}, a_{2}, b_{2}\right)=-3 a_{1} b_{1} b_{2}+2 a_{2}^{2}+\frac{1}{2} a_{1}^{2}+ \\
2 b_{2}^{2}-\frac{3}{2} a_{1}^{2} a_{2}+\frac{3}{2} b_{1}^{2} a_{2} \\
M\left(a_{1}, b_{1}, a_{2}, b_{2}\right)=a_{1}^{2}+b_{1}+a_{2}^{2}+b_{2}^{2}
\end{gathered}
$$

yang merupakan hampiran diskrit Hamilton dan Momentum.

Selanjutnya profil periodik gelombang jalan akan diperoleh dengan peminimuman $H(u)$ dengan kendala $M(u)=\gamma$.

Fungsi Lagrange untuk fungsi Hamilton $H(u)$ dengan kendala $M(u)=\gamma$ adalah

$$
L=H(u)+\lambda(M(u)-\gamma)
$$

dengan $\lambda$ adalah konstanta pengali Lagrange.

Persamaan ini akan didekati dengan fungsi lain yaitu:

$$
G=\|\nabla L\|^{2}
$$

Selanjutnya peminimuman dengan menggunakan Metode Steepest Decent dikenakan pada persamaan (12), diperoleh :

$$
X_{n+1}=X_{n-1}-h\left(\nabla G\left(X_{n-1}\right), \quad n=1,2,3, \ldots\right.
$$

Penggunaan Metode Steepest Decent pada permasalahan disini sulit dicari titik kritisnya. Oleh karena itu dalam menentukan ukuran langkah $h$ tidak digunakan ekspansi Taylor di titik kritis, namun dikenakan pada $G$. Sehingga memungkinkan untuk memperoleh $h$ yang tidak tunggal maupun kompleks. Hal ini dapat diantisipasi dengan memilih satu $h$ yang positif bila terdapat lebih dari satu yang real sedangkan untuk yang kompleks dipilih bagian realnya saja.

\section{HASIL DAN PEMBAHASAN}

Dengan melakukan peminimuman $H(u)$ dengan kendala $M(u)=\gamma$ menggunakan MAPLE (Program 1.) pada beberapa kasus yakni: $\gamma=0.1, \gamma=0.5, \gamma=1, \gamma=$ 2 , dan $\gamma=3$ dengan titik awal $(1,1,1,1,1)$ diperoleh hasil sebagai berikut (lihat Tabel 1. ):

Tabel 1: Hasil iterasi dengan mengunakan nilai awal $\left(a_{1}=1, b_{1}=1, a_{2}=1, b_{2}=1, \lambda=1\right)$

\begin{tabular}{|c|c|c|c|c|c|}
\hline$\gamma$ & Iterasi & $\mathbf{H}$ & $\mathbf{M}$ & $\mathbf{L}$ & $\mathbf{G}$ \\
\hline 0.1 & 217 & 0.04642204313 & 0.1000068337 & 0.04641910534 & 0.00000000000 \\
\hline 0.5 & 123 & 0.1719081382 & 0.5000107803 & 0.1719058806 & -0.00000000002 \\
\hline 1.0 & 104 & 0.2222222221 & 1.000025137 & 0.2222222226 & -0.000000000088 \\
\hline 2.0 & 102 & 0.0533021767 & 2.000007304 & 0.05330453508 & 0.00000000000 \\
\hline 3.0 & 73 & -0.402567126 & 3.000062623 & -0.4025307321 & 0.00000000000 \\
\hline
\end{tabular}

Sedangkan profil $u$ pada saat $\mathrm{t}=0$ untuk nilai $\gamma$ yang berbeda-beda dapat dilihat pada Gambar 1 .

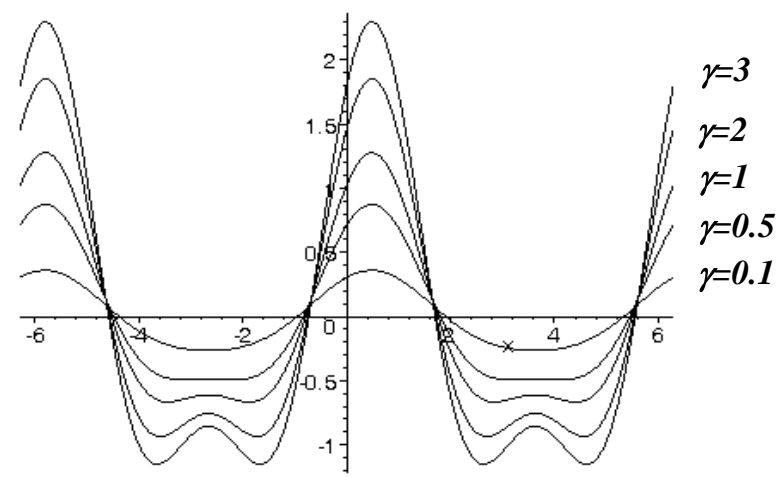

Gambar 1. Profil $\boldsymbol{u}$ pada saat $\mathrm{t}=\mathbf{0}$ untuk nilai $\boldsymbol{\gamma}$ yang berbeda-beda
Tentu saja dalam hal ini nilai minimum yang diperoleh belum bisa dipastikan kebenarannya, karena dalam kenyataannya nilai minimum disini sulit untuk ditentukan. Oleh karena itu dilakukan pengujian terhadap kehandalan program yang dibuat dengan melakukan peminimuman dengan menggunakan nilai awal yang berbeda-beda, apakah diperoleh nilai yang sama?

Dari hal tersebut dilakukan peminimuman dengan nilai awal yang berbeda-beda serta $\gamma=\mathbf{1}$ diperoleh hasil serpeti Tabel 2.

Dengan hasil ini sedikit memupus keraguan kita akan nilai minimum yang diperoleh, karena ternyata hasil yang diperoleh sama walaipun nilai awalnya berbeda.

Tabel 2. Hasil eksekusi menggunakan $\gamma=1$ dengan nilai awal yang berbeda-beda.

\begin{tabular}{|c|c|c|c|c|}
\hline Titik awal & Iterasi & $\mathbf{H}$ & $\mathbf{M}$ & $\mathbf{G}$ \\
\hline$(2,2,2,2,2)$ & 122 & 0.2222222222 & 1.000013380 & -0.000000000025 \\
\hline$(0.5,0.5,0.5,0.5,0.5)$ & 76 & 0.2222222221 & 1.000026752 & -0.000000000001 \\
\hline$(1,1,1,1,1)$ & 104 & 0.2222222221 & 1.000025137 & -0.000000000088 \\
\hline$(0.5,2,0.5,2,0.5)$ & 98 & 0.2222222220 & 1.000013284 & 0.000000000075 \\
\hline$(0.5,-2,0.5,-2,0.5)$ & 100 & 0.2222222223 & 1.000010647 & 0.000000000016 \\
\hline
\end{tabular}


Tabel 3: Koefisien Fourier untuk nilai awal $\left(\mathbf{a}_{1}=\mathbf{1}, \mathbf{b}_{1}=\mathbf{1}, \mathbf{a}_{2}=\mathbf{1}, \mathbf{b}_{2}=\mathbf{1}, \boldsymbol{\lambda}=\mathbf{1}\right)$

\begin{tabular}{|c|c|c|c|c|c|}
\hline$\gamma$ & $\cos \mathbf{x}$ & $\sin \mathbf{x}$ & $\cos \mathbf{2 x}$ & $\sin \mathbf{2 x}$ & $\boldsymbol{\lambda}$ \\
\hline 0.1 & 0.2771884121 & 0.1448788302 & 0.02667468875 & 0.03836648817 & -0.4298988670 \\
\hline 0.5 & 0.6012834239 & 0.3177150415 & 0.1091539778, & 0.1600362018 & -0.2094198377 \\
\hline 1.0 & 0.8327322733 & 0.4421157263 & 0.1867419181 & 0.2761217813 & 0.000018381 \\
\hline 2.0 & 1.150319290 & 0.6130473110 & 0.3058949902 & 0.4553834480 & 0.3228795142 \\
\hline 3.0 & 1.389423212 & 0.7416577445 & 0.4011105254 & 0.5988488095 & 0.5811660460 \\
\hline
\end{tabular}

Hasil yang diperoleh dalam Tabel 3. merupakan koefisien dari gelombang jalan $u$ pada saat $t=0$, dengan demikian misalkan untuk $\boldsymbol{\gamma}=\mathbf{0 . 1}$ diperoleh

$$
\begin{aligned}
u(x, 0)= & 0.2771935432 \cos x+ \\
& 0.1448818259 \sin x+ \\
& 0.02667680400 \cos 2 x+ \\
& 0.03836747658 \sin 2 x
\end{aligned}
$$

Dengan demikian persamaan (9) dapat diselesaikan secara numerik dengan menggunakan nilai awal $a_{1}(0)=0.2771935432, \quad b_{1}(0)=\mathbf{0 . 1 4 4 8 8 1 8 2 5 9}$ $a_{2}(0)=0.02667680400, b_{2}(0)=\mathbf{0 . 0 3 8 3 6 7 4 7 6 5 8}$, dengan bantuan MAPLE (Program 2).

Hasil solusi numerik ini berupa profil gelombang jalan yang bergantung pada waktu $(t)$ yang dapat dilihat pada gambar-gambar berikut.

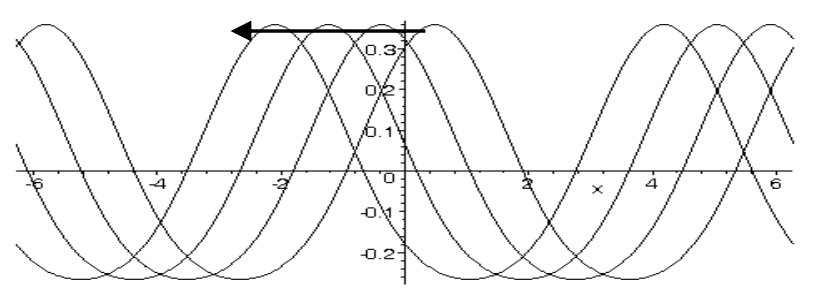

Gambar 2. Profil Gelombang jalan untuk $\gamma=0.1$ dan

$$
t=0,1,2,3
$$

Grafik diatas adalah merupakan gelombang jalan dari persamaan

$u(x, t)=a_{1}(t) \cos x+b_{1}(t) \sin x+a_{2}(t) \cos 2 x+b_{2}(t) \sin 2 x$

dimana $t=0,1,2,3$ dan $\gamma=0.1$.

Selanjutnya untuk $\gamma=0.5, \gamma=1, \gamma=2$ dan $\gamma=3$.

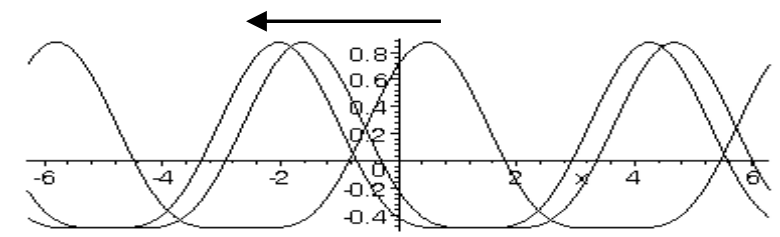

Gambar 3. Profil Gelombang jalan untuk $\gamma=0.5$ dan

$$
t=0,5,6
$$

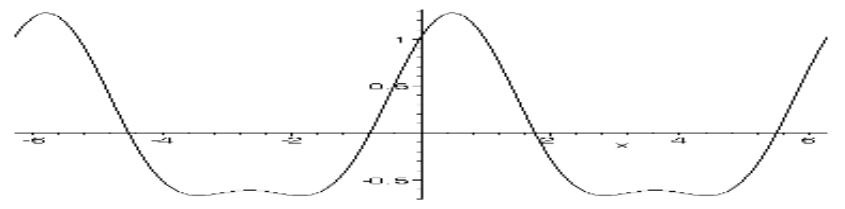

Gambar 4. Profil Gelombang untuk $\gamma=1$ dan $t=0,1,2,3$

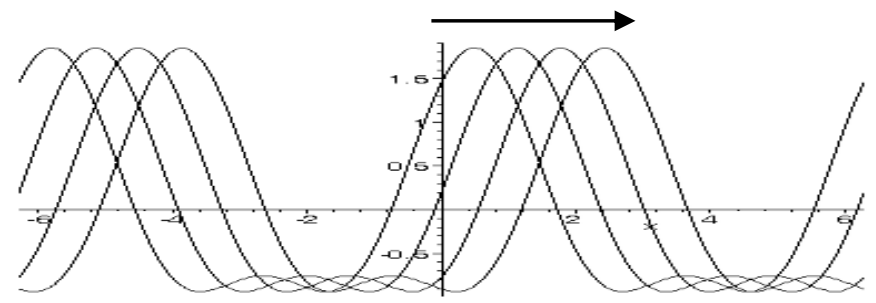

Gambar 5. Profil Gelombang jalan untuk $\gamma=2$ dan $t=0,1,2,3$

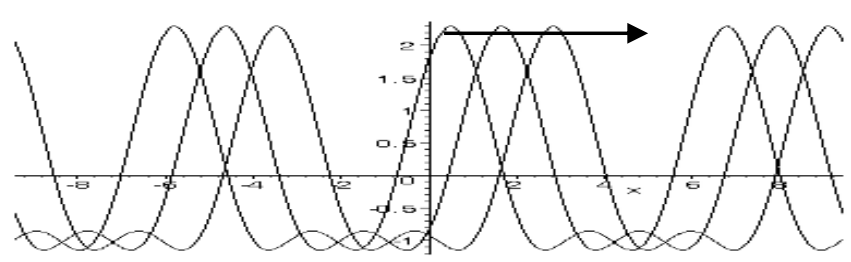

Gambar 6. Profil Gelombang jalan untuk $\gamma=3$ dan $t=0,1,2$

Hubungan $\lambda$ sebagai kecepatan rambat gelombang dengan $\lambda$ sebagai konstanta real pengali Lagrange

Dari proses peminimuman kita peroleh nilai $\lambda$ yang merupakan konstanta real dari fungsi Lagrange selanjutnya ditulis sebagai $\lambda_{2}$. Telah diketahui bahwa bentuk solusi gelombang jalan adalah $u(x, t)=u(x-\lambda t)$ dengan $\lambda$ menyatakan cepat rambat gelombang selanjutnya dinyatakan sebagai $\lambda_{2}$. Dengan melakukan explorasi (menggunakan Program 3) terhadap solusi gelombang jalan

$u\left(x-\lambda_{1} t\right)=a_{1} \cos \left(x-\lambda_{1} t\right)+b_{1} \sin \left(x-\lambda_{1} t\right)+a_{2} \cos 2\left(x-\lambda_{1}\right.$ $t)+b_{2} \sin 2\left(x-\lambda_{1} t\right)$

kemudian substitusikan koefisien-koefisiennya dengan hasil dari Tabel 3., misal untuk $\gamma=0.1$ maka akan dihasilkan plotting sebagai berikut: 


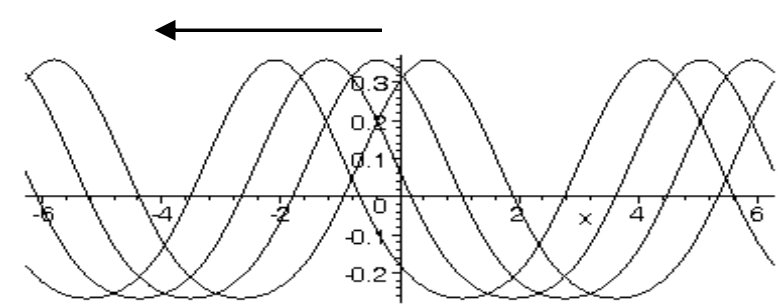

Gambar 7. Profil Gelombang jalan $\boldsymbol{u}\left(\boldsymbol{x}-\lambda_{1} t\right)$ untuk $\gamma=0.1, \lambda_{1}=2 \lambda_{2}$ dan $t=0,1,2,3$

Dengan menggunakan $\lambda_{1}=2 \lambda_{2}$ kita akan peroleh profil yang sama dengan yang diperoleh dengan menyelesaikan persamaan (10). Dalam hal ini dapat dilihat bahwa profil Gambar 2 dan Gambar 7 sama. Demikian juga untuk $\gamma=2$, seperti dari hasil eksekusi berikut dapat dilihat bahwa profil Gambar 5 dan Gambar 8 sama, hal inipun sama untuk $\gamma$ yang lainnya.

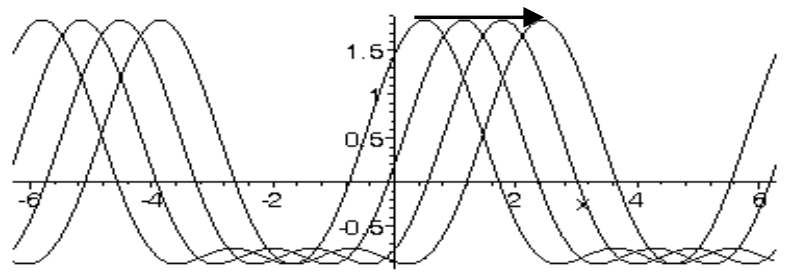

Gambar 8. Profil Gelombang jalan $\boldsymbol{u}(\boldsymbol{x}-\boldsymbol{\lambda 1} \boldsymbol{t})$ untuk $\gamma=2, \lambda_{1}=2 \lambda_{2}$ dan $t=0,1,2,3$

Sebagai catatan tambahan, nilai $\lambda$ yang diperoleh juga menentukan arah jalan gelombang. Untuk $\lambda$ negatif akan berjalan ke kiri sedangkan untuk $\lambda$ positif akan berjalan ke kanan.

\section{KESIMPULAN}

Berdasarkan pembahasan pada bagian sebelumnya dapat disimpulkan bahwa:

1. Peminimuman yang dilakukan untuk menentukan koefisien-koefiesien dari solusi persamaan KdV yang direpresentasikan dengan deret Fourier (persamaan 8), menghasilkan solusi :

$u(x, 0)=a_{1}(0) \cos x+b_{1}(0) \sin x+$

$$
a_{2}(0) \cos 2 x+b_{2}(0) \sin 2 x
$$

2. Selesaikan persamaan (10) dengan menggunakan nilai awal $a_{1}(0), b_{1}(0), a_{2}(0)$ dan $b_{2}(0)$ dari satu dengan pedekatan numerik. Sehingga akan diperoleh

$u(x, t)=a_{1}(t) \cos x+b_{1}(t) \sin x+a_{2}(t) \cos 2 x+$ $b_{2}(t) \sin 2 x$

yang merupakan solusi gelombang jalan yang diinginkan.

3. Terdapat hubungan yang erat antara kecepatan rambat gelombang dengan dengan konstanta pengali Lagrange, yakni kecepatan rambat gelombang jalan adalah dua kali konstanta pengali Lagrange. Hal ini dapat dilihat dari profil gelombang jalan pada gambar 2 dan gambar 7.
4. $\gamma>1$ akan menghasilkan $\lambda$ yang positif sehingga gelombang akan bergerak ke kanan, sedangkan $\gamma<1$ akan menghasilkan $\lambda$ yang negatif yang membuat gelombang bergerak ke kiri.

5. $\gamma=1$ gelombang kelihatan tidak merambat akibat dari kecepatan rambat gelombangnya cukup kecil (sekitar $\left.10^{-5}\right)$.

\section{DAFTAR PUSTAKA}

Boyke W.E.,DiPrima .R.C., 1992. Elementary Differential Equations and Boundary Value Problem, $5^{\text {th }}$ Edition, Willey, NewYork.

Suwono, E, 2002, Worksheet MAPLE Sistem Dinamik, ITB, Bandung

Coombers,K.R.,et al,1997 Differential Equation with $M A P L E, 2^{\text {nd }}$ Edition,John Wiley and Son, NewYork 


\section{LAMPIRAN PROGRAM}

\section{Program 1.}

$>$ restart: with (linalg) $: \mathrm{N}:=2$ :

$\mathrm{U}:=\operatorname{sum}(\mathrm{a}[\mathrm{k}] * \cos (\mathrm{k} * \mathrm{x})+\mathrm{b}[\mathrm{k}] * \sin (\mathrm{k} * \mathrm{x}), \mathrm{k}=1 \ldots \mathrm{N})$;

$\mathrm{H}:=\operatorname{simplify}\left(\operatorname{int}\left(1 / 2 * \operatorname{diff}(\mathrm{U}, \mathrm{x}) \wedge 2-\mathrm{U}^{\wedge} 3, \mathrm{x}=-\mathrm{Pi} . \mathrm{Pi}\right) / \mathrm{Pi}\right)$;

$\mathrm{M}:=\operatorname{simplify}\left(\right.$ int $\left(\mathrm{U}^{\wedge} 2, \mathrm{x}=-\mathrm{Pi}\right.$..Pi) / $\left.\mathrm{Pi}\right)$;

Warning, the protected names norm and trace have been redefined and unprotected

$$
\begin{gathered}
U:=a_{1} \cos (x)+b_{1} \sin (x)+a_{2} \cos (2 x)+b_{2} \sin (2 x) \\
H:=2 a_{2}^{2}+2 b_{2}^{2}+\frac{1}{2} a_{1}^{2}+\frac{1}{2} b_{1}{ }^{2}-3 a_{1} b_{1} b_{2}+\frac{3}{2} b_{1}{ }^{2} a_{2}-\frac{3}{2} a_{1}{ }^{2} a_{2} \\
M:=a_{1}{ }^{2}+a_{2}{ }^{2}+b_{2}{ }^{2}+b_{1}{ }^{2}
\end{gathered}
$$

$>$ Gamma: $=0.1$;

$\mathrm{L}:=\mathrm{H}+\mathrm{lambda}$ * (M-Gamma) ;

$$
\begin{aligned}
L:= & 2 a_{2}^{2}+2 b_{2}{ }^{2}+\frac{1}{2} a_{1}^{2}+\frac{1}{2} b_{1}^{2}-3 a_{1} b_{1} b_{2}+\frac{3}{2} b_{1}^{2} a_{2}-\frac{3}{2} a_{1}^{2} a_{2} \\
& +\lambda\left(a_{1}{ }^{2}+a_{2}{ }^{2}+b_{2}{ }^{2}+b_{1}{ }^{2}-.1\right)
\end{aligned}
$$

$>\operatorname{gradL}:=\operatorname{grad}(\mathrm{L},[\mathrm{a}[1], \mathrm{b}[1], \mathrm{a}[2], \mathrm{b}[2], \mathrm{lambda}])$ :

$>\mathrm{G}:=\operatorname{expand}\left(\operatorname{gradL}[1]^{\wedge} 2+\operatorname{gradL}[2]^{\wedge} 2+\operatorname{gradL}[3]^{\wedge} 2+\operatorname{gradL}[4]^{\wedge} 2+\operatorname{gradL}[5] \wedge 2\right)$;

$$
\begin{aligned}
G:= & -36 a_{1} b_{1} b_{2}+.8 a_{1}^{2}+15.8 b_{2}^{2}+15.8 a_{2}^{2}+.8 b_{1}^{2}+\frac{13}{4} b_{1}^{4}-36 b_{1} b_{2} \lambda a_{1} \\
& +2 a_{2}^{2} b_{2}^{2}+4 \lambda^{2} b_{2}^{2}+\frac{13}{4} a_{1}^{4}+a_{2}^{4}+b_{2}^{4}+.01+\frac{13}{2} b_{1}^{2} a_{1}^{2}+4 \lambda^{2} a_{2}^{2}+16 \lambda b_{2}^{2} \\
& +16 \lambda a_{2}^{2}+11 a_{1}^{2} b_{2}^{2}+11 b_{1}^{2} a_{2}^{2}+4 \lambda^{2} b_{1}^{2}+4 \lambda b_{1}^{2}+18 b_{1}^{2} a_{2} \lambda-18 a_{1}^{2} a_{2} \lambda \\
& +4 \lambda a_{1}^{2}+11 b_{1}^{2} b_{2}^{2}+11 a_{1}^{2} a_{2}^{2}+4 \lambda^{2} a_{1}^{2}-18 a_{1}^{2} a_{2}+18 b_{1}^{2} a_{2}
\end{aligned}
$$

$>\operatorname{gradG}:=\operatorname{grad}(\mathrm{G},[\mathrm{a}[1], \mathrm{b}[1], \mathrm{a}[2], \mathrm{b}[2], \mathrm{lambda}])$ :

$>\mathrm{x}[0]:=[1,1,1,1,1]$;

Gt [0]:=subs $(\mathrm{a}[1]=\mathrm{X}[0][1], \mathrm{b}[1]=\mathrm{X}[0][2], \mathrm{a}[2]=\mathrm{X}[0][3], \mathrm{b}[2]=\mathrm{X}[0][4], 1 \mathrm{ambda}=\mathrm{X}[0][5], \mathrm{G}$ ) ;

$$
\begin{aligned}
& X_{0}:=[1,1,1,1,1] \\
& G t_{0}:=78.21000000
\end{aligned}
$$

>iter: $=1000:$ epsilon: $=10^{\wedge}(-10)$ :

for $i$ from 1 to iter while abs(Gt[i-1]) > epsilon do

$x[i]:=\operatorname{evalm}(X[i-1]-h *$ subs $(a[1]=X[i-1][1], b[1]=X[i-1][2], a[2]=X[i-1][3], b[2]=X[i-$ 1] [4], lambda $=X[i-1][5], \operatorname{evalm}(\operatorname{gradG})))$;

Gth:=expand (subs (a [1]=X[i] [1],b[1]=X[i][2], a [2]=X[i][3],b[2]=X[i] [4], lambda=X[i] $[5], G))$ :

dGth:=diff $(G t h, h) ; v:=f s o l v e(d G t h, h, \operatorname{maxsols}=1$, real) ;

if $\mathrm{Gth}=0$ then $\mathrm{ht}[i]:=0.2$ else

ht $[i]:=a b s(v)$ end if;

$x[i]:=\operatorname{evalm}(x[i-1]-h t[i] * \operatorname{subs}(a[1]=x[i-1][1], b[1]=x[i-1][2], a[2]=x[i-$

1] [3], b[2]=X[i-1] [4], lambda=X[i-1][5], evalm(gradG)));

Gt [i] :=subs $(a[1]=X[i][1], b[1]=X[i][2], a[2]=X[i][3], b[2]=X[i][4], 1 a m b d a=X[i][5], G$ ) ;

sumiter:=i;od:

$>$ for $k$ from sumiter-5 to sumiter do

$\mathrm{h}[\mathrm{k}]:=\mathrm{ht}[\mathrm{k}] ; \mathrm{X}[\mathrm{k}]:=\operatorname{simplify}(\mathrm{X}[\mathrm{k}]) ; \mathrm{Gt}[\mathrm{k}]:=\mathrm{Gt}[\mathrm{k}] ; \mathrm{od}$;

$$
h_{212}:=.06539041053
$$




$$
\begin{gathered}
X_{212}:=[.2771909949, .1448804670, .02667622893, .03836678184,-.4298949882] \\
G t_{212}:=.110^{-9} \\
h_{213}:=.1158866570 \\
X_{213}:=[.2771904060, .1448798365, .02667529805, .03836711950,-.4298960325] \\
G t_{213}:=.110^{-9} \\
h_{214}:=.06538836038 \\
X_{214}:=[.2771898953, .1448798813, .02667598078, .03836648206,-.4298965862] \\
G t_{214}:=.110^{-9} \\
h_{215}:=.1158888010 \\
X_{215}:=[.2771893608, .1448793090, .02667513594, .03836678858,-.4298975340] \\
G t_{215}:=.210^{-9} \\
h_{216}:=.06539043744 \\
X_{216}:=[.2771888973, .1448793496, .02667575560, .03836621001,-.4298980366] \\
G t_{216}:=.110^{-9} \\
h_{217}:=.1159011613
\end{gathered}
$$

$>$ jumlah iterasi:=sumiter;

nilai_H:=subs (a [1] =x[sumiter] [1], b[1]=X[sumiter] [2], a [2]=X[sumiter] [3], b [2] =x[su miter] $[4], \mathrm{H})$;

nilai_M:=subs (a [1] =x[sumiter] [1],b[1]=X[sumiter] [2], a [2]=X[sumiter] [3],b[2]=X[su $\operatorname{miter} \overline{]}[4], M)$;

nilai_L:=subs (a [1] =x[sumiter] [1],b[1] =x[sumiter] [2], a [2] =X[sumiter] [3],b[2]=X[su miter] [4], lambda=X [sumiter] [5], L);

nilai_G:=Gt [sumiter] ;

Ubaru : $=x[$ sumiter] [1] * $\cos (x)+x[$ sumiter] [2]*sin $(x)+x[$ sumiter] [3] $* \cos (2 * x)+x[$ sumite r] [4]* $\sin (2 * x)$;

$$
\begin{gathered}
\text { jumlah_iterasi }:=217 \\
\text { nilai_H }:=.04642204313 \\
\text { nilai_ } M:=.1000068337 \\
\text { nilai_L }:=.04641910534 \\
\text { nilai_G }:=0 .
\end{gathered}
$$

Ubaru $:=.2771884121 \cos (x)+.1448788302 \sin (x)+.02667498875 \cos (2 x)$

$$
+.03836648817 \sin (2 x)
$$

\section{catatan:}

Karena proses peminimuman di sini dikenakan pada persamaan (12) yang dalam hal ini bernilai nol, maka kriteria penghentian dalam iterasi adalah jika $|G|<10^{-10}$ yang merupakan batasan galat.

\section{Program 2.}

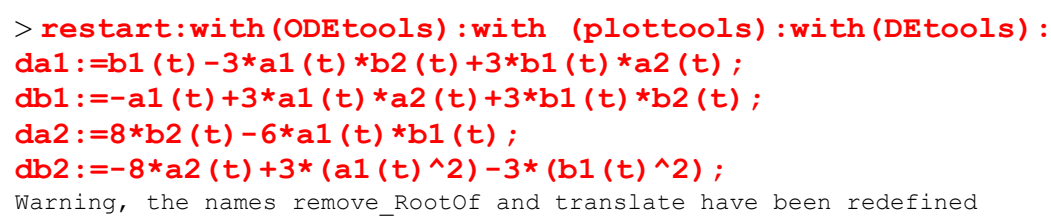




$$
\begin{gathered}
d a 1:=\mathrm{b} 1(t)-3 \mathrm{a} 1(t) \mathrm{b} 2(t)+3 \mathrm{~b} 1(t) \mathrm{a} 2(t) \\
d b 1:=-\mathrm{a} 1(t)+3 \mathrm{a} 1(t) \mathrm{a} 2(t)+3 \mathrm{~b} 1(t) \mathrm{b} 2(t) \\
d a 2:=8 \mathrm{~b} 2(t)-6 \mathrm{a} 1(t) \mathrm{b} 1(t) \\
d b 2:=-8 \mathrm{a} 2(t)+3 \mathrm{a} 1(t)^{2}-3 \mathrm{~b} 1(t)^{2}
\end{gathered}
$$

$>\operatorname{gg}:=\operatorname{dsolve}(\{\operatorname{diff}(\mathrm{a} 1(t), t)=\operatorname{da} 1, \operatorname{diff}(\mathrm{b} 1(t), t)=\operatorname{db} 1, \operatorname{diff}(a 2(t), t)=\operatorname{da} 2$,

$\operatorname{diff}(b 2(t), t)=d b 2, a 1(0)=0.2771884121, b 1(0)=0.1448788302, a 2(0)=0.02667468875, b 2(0)=$ $0.03836648817\},\{a 1(t), b 1(t), a 2(t), b 2(t)\}$, type=numeric, output=listprocedure) :

$\mathrm{a}[1]:=\operatorname{subs}(g g, \mathrm{a} 1(\mathrm{t})): \mathrm{b}[1]:=\operatorname{subs}(g g, \mathrm{~b} 1(\mathrm{t})): \mathrm{a}[2]:=\operatorname{subs}(g g, \mathrm{a} 2(\mathrm{t})): \mathrm{b}[2]:=\operatorname{subs}(g g, \mathrm{~b} 2(t)):$

$>$ with (plots) $: m:=3$ :

for $t$ from 0 to $m$ do

$u[t]:=a[1](t) * \cos (x)+b[1](t) * \sin (x)+a[2](t) * \cos (2 * x)+b[2](t) * \sin (2 * x)$;

p1 $[t]:=p l o t(u[t], x=-2 * P i . .2 * P i): o d:$

Warning, the name changecoords has been redefined >display $([\operatorname{seq}(\mathbf{p} 1[t], t=0 . . m)])$;

\section{Program 3}

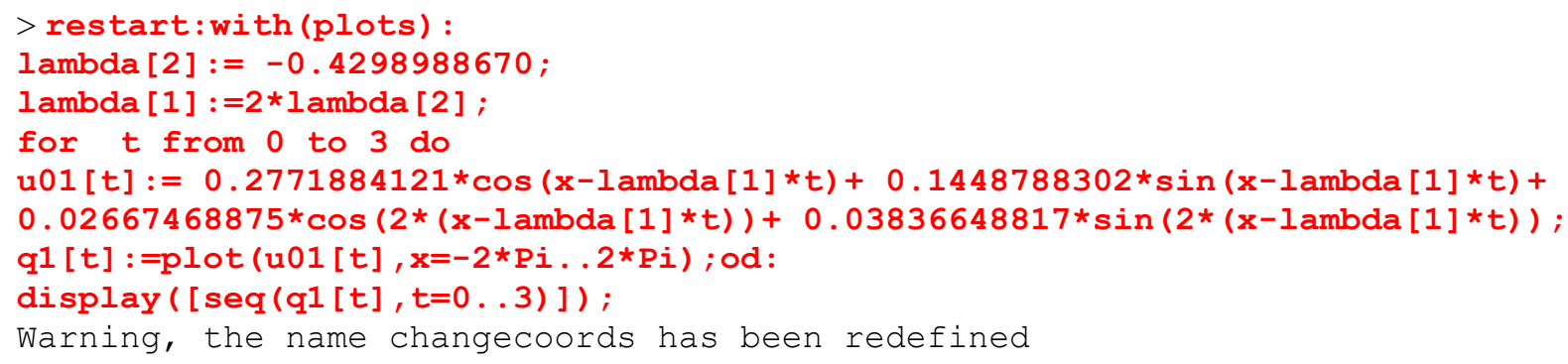

$$
\begin{aligned}
& \lambda_{2}:=-.4298912838 \\
& \lambda_{1}:=-.8597825676
\end{aligned}
$$


